\title{
Quality of life measurement in bone metastases: A literature review
}

\author{
Sukirtha Tharmalingam \\ Edward Chow \\ Kristin Harris \\ Amanda Hird \\ Emily Sinclair \\ Rapid Response Radiotherapy \\ Program, Odette Cancer Centre, \\ Sunnybrook Health Sciences Centre, \\ University of Toronto, Toronto, \\ Canada
}

\begin{abstract}
Quality of life (QOL) has become an important consideration in the care of patients with bone metastases as prevalence, incidence and patient survival are on the rise. As a result, more interventional studies now measure patient's QOL as a meaningful endpoint. However, well-developed bone metastases specific quality of life instruments are lacking. A literature review was conducted to better understand the nature of QOL instruments used in bone metastases trials. A total of 47 articles evaluating QOL in patients with bone metastases were identified. Twentyfive different instruments were used to evaluate QOL with study-designed questionnaires and the EORTC QLQ-C30 being most commonly employed. Many studies used more than one scale or instrument to measure QOL. This makes it difficult to compare QOL in bone metastases patients across studies and come to any formal conclusions. Therefore, this review demonstrates the need to develop a bone module that can be used across countries in future clinical trials.
\end{abstract}

Keywords: bone metastases, quality of life, QOL instrument, review

\section{Introduction}

Bone metastases are a significant cause of morbidity and skeletal complications in many cancer patients. Primary tumors of the breast and prostate are the most common to metastasize to the bone, with a post-mortem incidence of approximately $70 \%$ (Coleman 2006). Primary tumors of the lung, thyroid, and kidney also metastasize to the bone with a post-mortem incidence of approximately $30 \%$ to $40 \%$ (Perez et al 2004). The morbidity associated with metastatic bone diseases includes pain, hypercalcemia, pathological fractures, spinal instability, cord compression, and immobility (Manoso and Healey 2005).

Treatment options for bone metastases have expanded to include orthopedic interventions, newer generations of bisphosphonates and systemic therapy. With recent advances in effective treatment options and a multidisciplinary approach to cancer management, the survival of patients with bone metastases has increased. Consequently, an increasing number of people are living longer years with bone metastases and the need to maximize their quality of life (QOL) during these years is essential.

The World Health Organization defines health as "a state of complete physical, mental and social well-being and not merely the absence of disease or infirmity" (World Health Organization 1948). This multidimensional definition of health has encouraged health care professionals and clinical trials investigators to incorporate all aspects of health in treatment. Consequently, an increasing emphasis has been placed on QOL as an outcome measurement endpoint in clinical trials. Over the last three decades there has been an explosion of QOL studies in medical literature. A Medline search using "quality of life" as a keyword reveals a significant increase in the number of articles related to the topic over a period of 30 years, from 32 in 1973 to 5444 in 2004 (Siddiqui et al 2006).

Quality of life has become an important consideration in the management of bone metastases. QOL instruments help health care professionals to better understand the 
impact of new or existing treatments on various aspects of a patient's life. Recently, site-specific QOL instruments have been developed as the issues plaguing cancer patients differ depending on their symptoms, course of treatment and future outlook. However, bone metastases specific QOL instruments are lacking. The objective of this study was to review the QOL instruments that have been used in previous bone metastases trials.

\section{Methods}

A literature review was conducted in July 2006 using Medline (PubMed) from OVID registries for any studies measuring QOL in patients with bone metastases from 1966 to June 2006. The keywords used were "bone neoplasms", "bone metastases" and "quality of life (QOL)". Studies involving a patient cohort with metastases sites other than the bone were excluded in hopes to better understand the specificity of instruments used in bone metastases trials alone. Any individual case reports, qualitative studies or review articles were also excluded.

\section{Results}

Forty-seven trials measuring QOL in patients with bone metastases were identified. Table 1 presents the patient population number, treatment setting, and assessment tools in each study. Of the 47 studies, 18 included bisphosphonate treatments, 12 included surgical/orthopedic interventions, 8 involved radiotherapy and 9 investigated other treatment options for patients with bone metastases (Table 2). The 47 studies involved a total of 10,844 patients. The number of participants in the studies ranged from 7-1,171 with a median number 85 .

A total of 24 different instruments were used to evaluate QOL including pain assessment scales, validated QOL instruments, and study-designed questionnaires (Table 3). The number of instruments used in each study varied. Excluding pain measurements other than the BPI or PPI, the number of instruments used to measure QOL ranged from 1 to 4 . Of the 47 studies, $21(45 \%), 17(36 \%), 7(15 \%)$, and $2(4 \%)$ of the studies used 1, 2, 3, and 4 instruments, respectively. Most studies employed study-designed questionnaires ( $n=10,21 \%$ ) or the European Organization for Research and Treatment of Cancer Quality of Life Questionnaire version 3 (EORTC QLQ-C30) (n=10, 21\%) as assessment tools.

\section{Summary of quality of life instruments employed}

The EORTC QLQ-C30 is a validated questionnaire used to evaluate the quality of life of cancer patients. It consists of
30 questions incorporating five functional scales (physical functioning, role functioning, cognitive functioning, emotional functioning and social functioning), 3 symptom scales (fatigue, pain, and nausea and vomiting), and a global health scale. The remaining items assess other symptoms commonly reported by cancer patients (dyspnea, appetite loss, sleep disturbance, constipation and diarrhea), as well as perceived financial difficulties associated with the disease and its treatment (Aaronson et al 1993). Ten out of the 47 studies used the EORTC QLQ-C30 (Kristensen et al 1999; Osoba et al 1999; DiLorenzo et al 2002; Smeland et al 2003; Body et al 2004; Collette et al 2004; Diel et al 2004; Jenlev et al 2005; Wardley et al 2005; Kaasa et al 2006). The EORTC QLQ-C30 is also supplemented by site-specific modules such as the BR 23 as used by Wardley and colleagues (2005). The BR23 consists of 23 breast cancer-specific questions focusing on the side effects of therapy, body image, sexuality and outlook for the future.

Study-designed assessments were used in 10 publications (van Holtzen-Verzantvoort et al 1991; van HoltzenVerzantvoort et al 1993; Creswell 1995; van HoltzenVerzantvoort et al 1996; Nair et al 1999; Osoba et al 1999; Schoeggl et al 2002; Hirabayashi et al 2003; van den Hout et al 2003; Anselmetti et al 2004). For example, Cressewell and colleagues (1995) did not use the EORTC QLQ-C30 or any other established questionnaires but did design a diseasespecific questionnaire addressing patients' perspectives on physical activity limitations and treatment expectations. This suggested the lack of a bone metastases-specific instrument. However, the use of a variety of study-designed assessments does not allow for outcome comparison between studies.

The Functional Assessment of Cancer Therapy-General questionnaire (FACT-G) is a multidimensional questionnaire developed and validated in cancer patients to measure the changes in the 4 main domains of the quality of life: physical well-being ( 7 items), social/family well-being ( 7 items), emotional well-being ( 6 items) and functional well-being ( 7 items) (Cella et al 1993). As with the EORTC QLQ-C30, the FACT-G is also designed for cancer patients in general. The FACT-G was used to evaluate QOL in 5 articles (Vitale et al 2001; Saad et al 2002; Vogel et al 2004; Weinfurt et al 2004, 2005).

The Edmonton Symptom Assessment System (ESAS) is a validated 9 -item, patient-rated, symptom verbal rating scale with domains in global pain, nausea, tiredness, depression, anxiety, drowsiness, appetite, sense of well-being, and shortness of breath (Bruera et al 1991). The ESAS was designed to assess the multidimensional nature of quality of life specific to palliative care and has been demonstrated to be valid and 


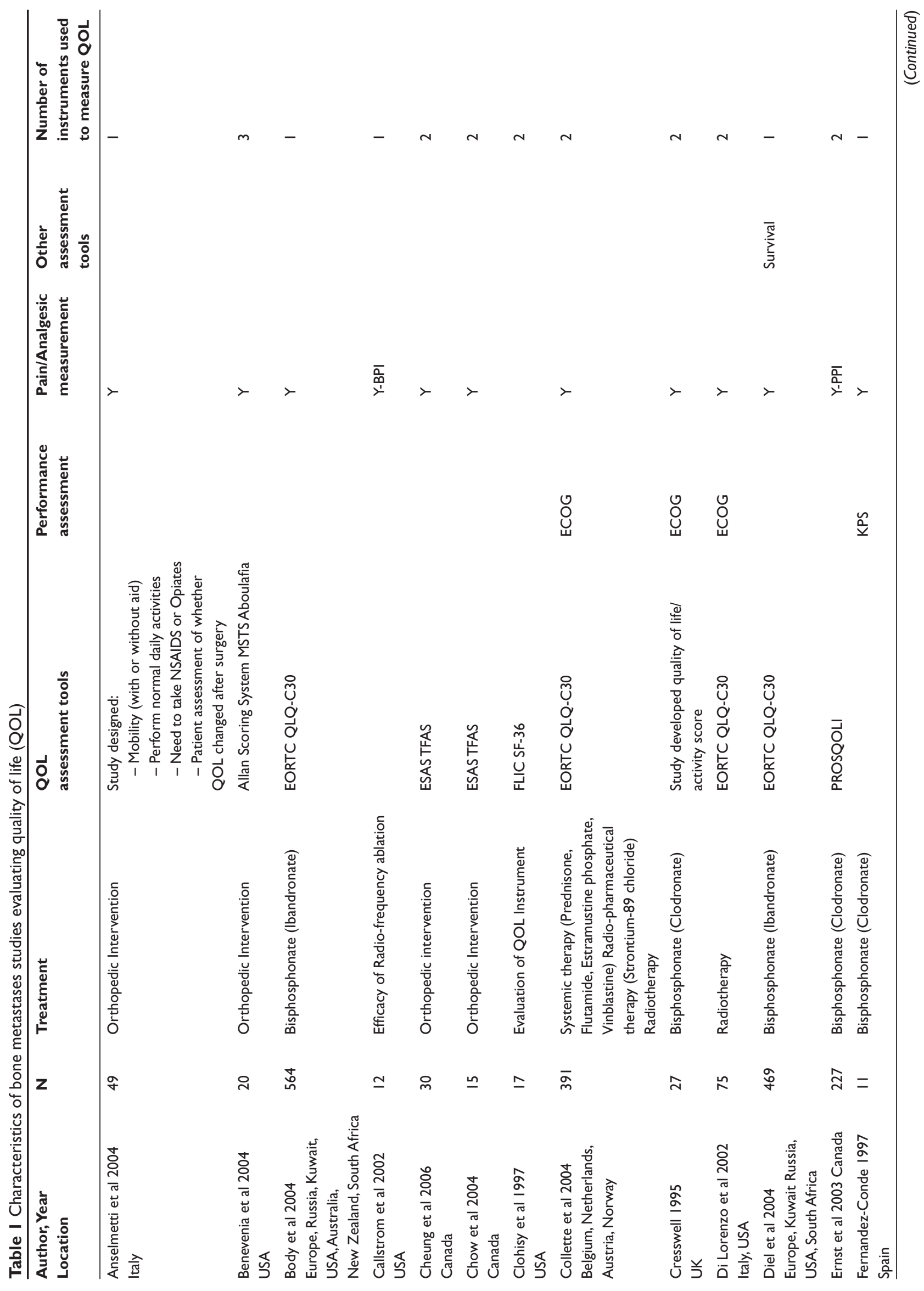




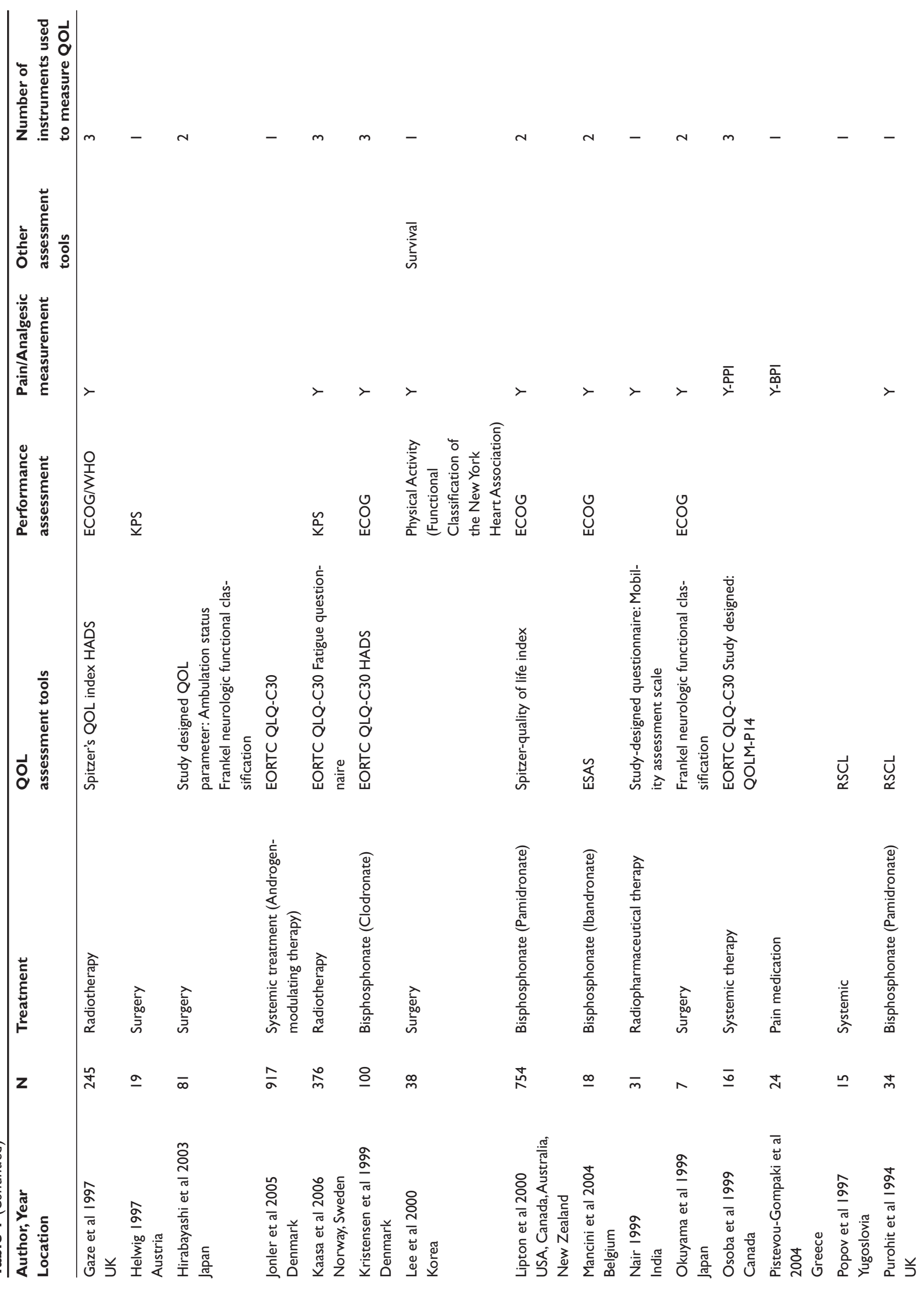




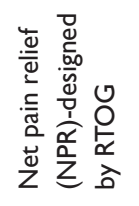

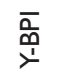

ญ

ญ

$\frac{\text { 殅 }}{2}$

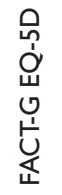

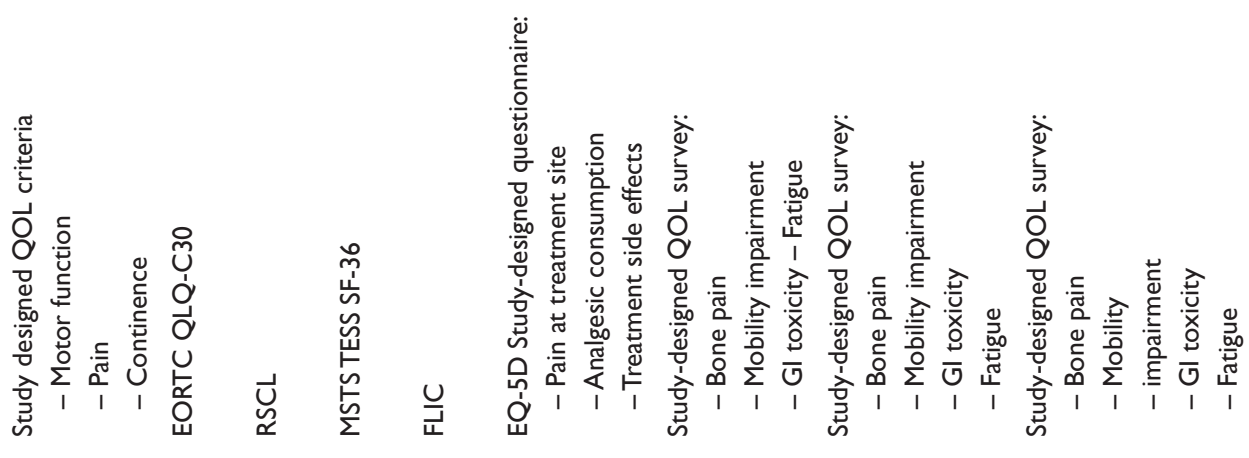

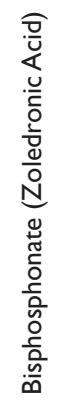
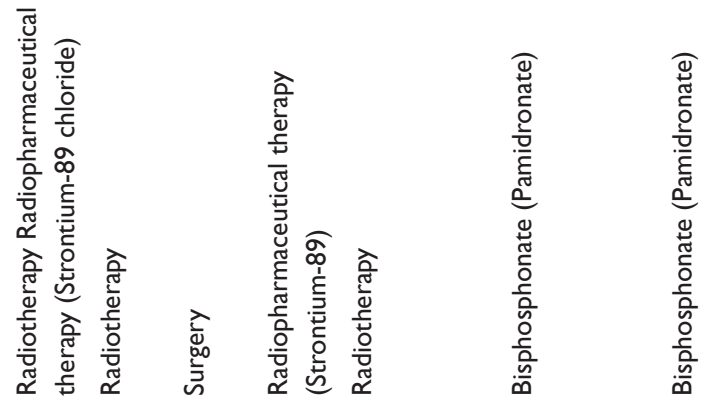

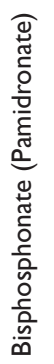

?̊.

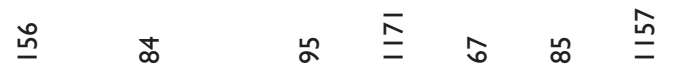

$\stackrel{ \pm}{\underline{\sigma}}$

声
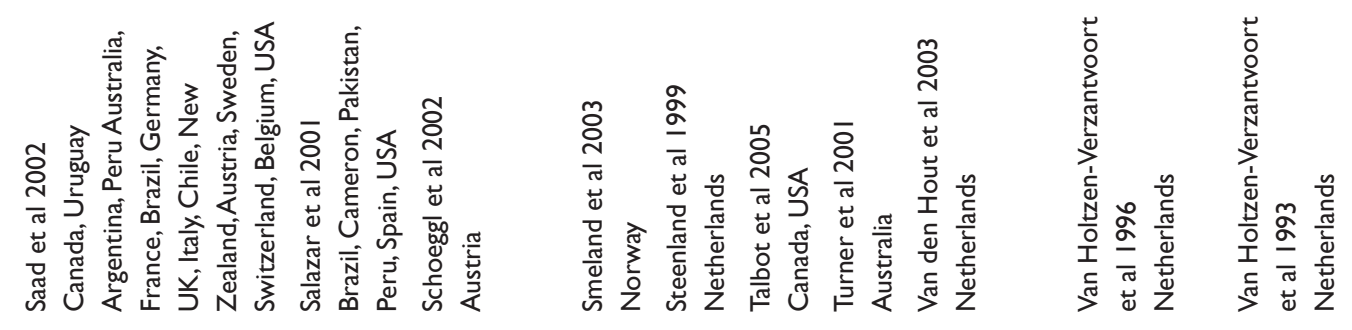

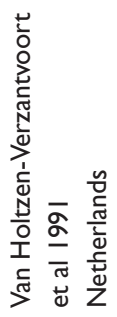




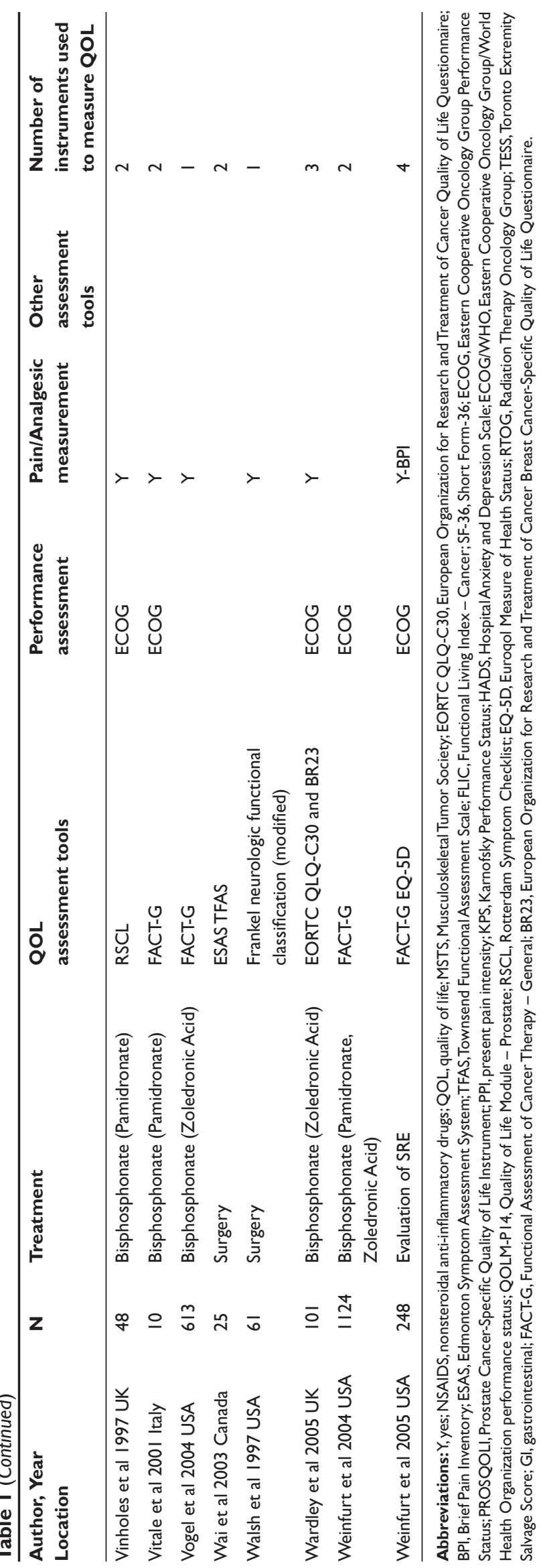

reliable in patients with terminal cancer (Bruera et al 1991). The ESAS was used in 4 of the articles (Wai et al 2003; Chow et al 2004; Mancini et al 2004; Cheung et al 2006).

The Rotterdam Symptom Checklist (RSCL), used in 4 of the articles (Purohit et al 1994; Popev et al 1997; Vinholes et al 1997; Steenland et al 1999), is a tool used to measure the psychological and physical distress in cancer patients. The RSCL consists of 38 items covering 3 domains: physical symptoms, psychological symptoms and activities of daily living (de Haes et al 1990).

The Brief Pain Inventory (BPI) evaluates patient's worst, average and current pain, analgesic consumption and the pain relief from medication. Pain interference with daily living is evaluated with questions concerning general activity, mood, walking ability, normal work, relations with other people, sleep, and enjoyment of life (Cleeland and Ryan 1994). While the BPI is an excellent measure of pain intensity and interference, it is not a complete measurement of overall QOL and is often accompanied by other tools. Four articles in this review used the BPI to measure quality of life (Callstrom et al 2002; Saad et al 2002; Pistevou-Gompaki et al 2004; Weinfurt et al 2005).

The EuroQol classification system (EQ-5D) is a generic health-related QOL instrument, designed for cost-utility analyses and comparisons of therapeutic effects across different diseases. The EQ-5D has five attributes (mobility, self-care, usual activities, pain/discomfort, and anxiety/depression) (Brooks et al 2003). Three articles used the EQ-5D (Saad et al 2002; van den Hout et al 2003; Weinfurt et al 2005).

The Townsend Functional Assessment Scale (TFAS) is a classification of a patient's functional capabilities using four categories: normal pain-free function, normal function but with pain, significantly limited function requiring prostheses, and nonfunctional (Townsend et al 1994). Three articles used the TFAS (Wai et al 2003; Chow et al 2004; Cheung et al 2006).

The Frankel classification system was developed by the American Spinal Injury Association in spinal cord injuries (Frankel 1969). Three studies used the Frankel classification to measure neurological status of bone metastases patients in the surgery setting to categorize the degree of motor, sensory, and autonomic involvement (Hirabyashi et al 2001; Okuyama et al 1999; Walsh et al 1997).

The following instruments were used in two studies each:

The Functional Living Index: Cancer (FLIC) is a validated QOL instrument used to evaluate the effect of the symptoms of cancer and its treatment on functional ability in all areas of life (Schipper et al 1984). The Hospital Anxiety 
Table 2 Study treatment settings

\begin{tabular}{ll}
\hline Treatment & Number of studies \\
\hline Bisphosphonates & $18(38 \%)$ \\
Surgical and orthopedic intervention & $12(26 \%)$ \\
Radiotherapy & $8(17 \%)$ \\
Other & $9(19 \%)$ \\
Systemic therapy & $4(9 \%)$ \\
Radiofrequency abalation & $2(4 \%)$ \\
Skeletal events evaluation & $\mathrm{I}(2 \%)$ \\
Pain & $\mathrm{I}(2 \%)$ \\
Total & 47 \\
\hline
\end{tabular}

and Depression Scale (HADS) consists of 14 statements relating to anxiety and depression based on patient experience over the past week (Zigmond and Snaith 1983). The Musculoskeletal Tumor Society (MSTS) functional assessment form measures functional outcomes in patients

Table 3 Frequency of instruments used in clinical trials measuring quality of life in patients with bone metastases

\begin{tabular}{|c|c|}
\hline Instrument & Frequency \\
\hline ECOG (WHO) Performance Scores & 15 \\
\hline Study-designed assessment & 10 \\
\hline EORTC QLQ-C30 & 10 \\
\hline $\begin{array}{l}\text { Functional Assessment of Cancer } \\
\text { Therapy - General (FACT-G) }\end{array}$ & 5 \\
\hline Rotterdam Symptom Checklist (RSCL) & 4 \\
\hline Karnofsky Performance Score (KPS) & 4 \\
\hline Edmonton Symptom Assessment Scale (ESAS) & 4 \\
\hline Brief Pain Inventory (BPI) & 4 \\
\hline EuroQol 5D (EQ-5D) & 3 \\
\hline Townsend Functional Assessment Scale (TFAS) & 3 \\
\hline Frankel Classification (Neurological status) & 3 \\
\hline Functional Living Index: Cancer (FLIC) & 2 \\
\hline Hospital Anxiety and Depression Scale (HADS) & 2 \\
\hline MSTS & 2 \\
\hline Present Pain Intensity scale (PPI) & 2 \\
\hline SF-36 & 2 \\
\hline Spitzer's quality of life index & 2 \\
\hline Aboulafia Scoring System & 1 \\
\hline Allan Scoring System & 1 \\
\hline BR23 & I \\
\hline Fatigue Questionnaire & I \\
\hline $\begin{array}{l}\text { Physical Activity (Functional Classification } \\
\text { of the New York Heart Association) }\end{array}$ & 1 \\
\hline $\begin{array}{l}\text { Prostate Cancer Specific Quality of } \\
\text { Life Instrument (PROSQOLI) }\end{array}$ & 1 \\
\hline Toronto Extremity Salvage Score (TESS) & I \\
\hline
\end{tabular}

with musculoskeletal tumors. The evaluation scores are determined by the restriction in activities (actual or prohibited) and the effect of these restrictions on the patient's lifestyle (Enneking 1987; Enneking et al 1993). The Short Form-36 (SF-36) is a validated generic tool used to evaluate overall health status in eight domains consisting of: physical functioning, role limitations secondary to physical problems, bodily pain, general health, vitality, social functioning, role limitations because of emotional problems and mental health (Ware 1993). The Spitzer's quality of life index has five items concerning activity, daily living, health, support and outlook each rates according the verbal description that most closely reflects the patient's status (Spitzer et al 1981). The Present Pain Intensity (PPI) is a six-point pain intensity scale of the McGill-Melzack Pain Questionnaire (Melzack 1975).

The following measurements were used in one study each:

The Toronto Extremity Salvage Score (TESS) evaluates physical disability in patients treated for extremity tumors. The TESS includes 30 items on activity limitations in daily life such as restrictions in body movement, mobility, selfcare, and performance of daily tasks (Davis et al 1996). The Allan Scoring System is used to assess pain, independence and ambulation ability (Allan et al 1995). The Aboulafia Scoring System scale is a scoring system for saddle reconstruction and is used to evaluate clinical function in patients post-operatively (Aboulafia et al 1995). The fatigue questionnaire was developed for a hospital based study of chronic fatigue syndrome consisting of 11 items including domains such as physical and mental aspects of fatigue, duration of fatigue, percent of time the respondent felt fatigue, and muscle pain during rest and exercise (Kaasa et al 2006). The Prostate Cancer Specific Quality of Life Instrument (PROSQOLI) uses a series of nine linear analog scale related to pain, physical activity, fatigue, appetite, constipation, passing urine, family/marriage relationships, mood, and overall well being (Ernst et al 2003).

Other endpoints utilized especially in studies investigating bisphosphonates include the monitoring the occurrence of skeletal related events such as hypercalcemia, pathological fractures, spinal cord compression, use of surgery and radiation.

\section{Pain assessment}

Thirty-nine of the studies measured the intensity and frequency of bony pain, its impact on function and physical activities, and analgesic consumption. Of the 8 studies that did not specifically evaluate pain, 6 utilized validated QOL instruments (EORTC QLQ-C30, FACT-G, FLIC, SF-36, 
MSTS, TESS, ESAS, TFAS, RSCL), which include painrelated questions. Of the two remaining studies, one used a performance score while the other used an evaluation of neurological function and study-designed questionnaire evaluating ambulation.

\section{Performance evaluation}

Forty-three percent of the studies $(n=20)$ measured performance status in addition to QOL. The ECOG was the most commonly employed ( $\mathrm{n}=15[75 \%])$, however the KPS was also used $(n=4[20 \%])$. Lee and colleagues (2000) used the Functional Classification of the New York Heart Association to evaluate performance status and measure QOL. Helwig and colleagues (1997) utilized the KPS alone to evaluate QOL while Fernandez-conde and colleagues (1997) evaluated QOL using the KPS and monitoring analgesic consumption.

\section{Conclusion}

Quality of life in patients with bone metastases is increasingly considered an essential outcome for clinical trials and patient management and therefore good assessment tools are of increasing importance. In recent years, a vast number of QOL instruments have been developed, including several instruments for the general cancer population. However, to date, none are specific to the problems associated with bone metastases.

Research in the field of bone metastases has focused on pain and its associated outcomes. However, QOL is affected by many factors other than pain, including limited mobility, reduced performance, side effects and impaired role functioning. Hence a wider range of end-points are required with greater sensitivity than those currently employed (Barton et al 2001).

From this review, there is increased evidence that an instrument incorporating pain from bone metastases along with other issues arising from skeletal complications as well as psychosocial domains is needed to improve the understanding of QOL in patients with bone metastases. Recently, Androver and colleagues (2005) developed a 35-item questionnaire using patient cohorts from different cancer centers in Spain. The domains identified were: pain, daily activities, mobility, energy/vitality, adjustment and coping, sexual activities, feelings, and health perception. However, this instrument has yet to be validated in different ethnic and cultural backgrounds. Another effort to develop a bone module across different countries that is coordinated by the EORTC-QLG is also currently underway.

\section{Acknowledgments}

This project is generously supported by a grant from the National Cancer Institute of Canada and an unrestricted educational grant from Novartis Oncology. The development of bone module is supervised by EORTC QLG.

\section{References}

Aaronson NK, Ahmedzai S, Bergman B, et al. 1993. The European Organization for Research and Treatment of Cancer QLQ-C30: a quality-of-life instrument for use in international clinical trials in oncology. J Natl Cancer Inst, 85:365-76.

Aboulafia AJ, Buch R, Mathews J, et al. 1995. Reconstruction using the saddle prosthesis following excision of primary and metastatic periacetabular tumors. Clin Orthop Relat R, 314:203-13.

Allan DG, Bells RS, Davis A, Langer F. 1995. Complex acetabular reconstruction for metastatic tumor. J Arthroplasty, 10:301-6.

Adrover E, Allepuz J, Sureda A, et al. 2005. Development of a questionnaire to measure health-related quality of life (HRQOL) in patients with bone metastases (BOMET-QOL). J Outcom Res, 9:15-27.

Barton MB, Dawson R, Jacob S, et al. 2001. Palliative radiotherapy of bone metastases: an evaluation of outcome measures. J Eval Clin Pract, 7:47-64.

Benevenia J, Cyran FP, Biermann JS, et al. 2004. Treatment of advanced metastatic lesions of the acetabulum using the saddle prosthesis. Clin Orthop Relat R, 426-23-31.

Body J, Diel IJ, Bell R, et al. 2004. Oral ibandronate improves bone pain and preserves quality of life in patients with skeletal metastases due to breast cancer. Pain, 111:306-12.

Brooks R, Rabin R, de Charro F (eds). 2003. The Measurement and Valuation of Health Status Using EQ-5D: A European Perspective: Evidence from the EuroQol BIO MED Research Programme. Rotterdam: Kluwer Academic Publishers.

Bruera E, Kuehn N, Miller M, et al. 1991. The Edmonton symptom assessment system (ESAS): a simple method for the assessment of palliative care patients. J Palliat Care, 7:6-9.

Callstrom MR, Charboneau JW, Goetz MP, et al. 2002. Painful metastases involving bone: feasibility of percutaneous CT- and US-guided radiofrequency ablation. Radiology, 224:87-97.

Carlson LE, Koski T, Gluck S. 2001. Longitudinal effects of high-dose chemotherapy and autologous stem cell transplantation on quality of life in the treatment of metastatic breast cancer. Bone Marrow Transpl, 27:989-98.

Cella DF, Tulsky DS, Gray G, et al. 1993. The Functional Assessment of Cancer Therapy (FACT) scale: Development and validation of the general measure. J Clin Oncol, 11:570-9.

Cheung G, Chow E, Holden L, et al. 2006. Percutaneous vertebroplasty in patients with intractable pain from osteoporotic or metastatic fractures: a prospective study using quality-of-life assessment. Can Assoc Radiol J, 57:13-21.

Chow E, Holden L, Danjoux C, et al. 2004. Successful salvage using percutaneous vertebroplasty in cancer patients with painful spinal metastases or osteoporotic compression fractures. Radiother Oncol, 70:265-7.

Cleeland CS, Ryan KM. 1994. Pain assessment: global use of the Brief Pain Inventory. Ann Acad Med Singapore, 23:129-38.

Clohisy DR, Le CT, Umen AJ. 1997. Measuring health status in patients with skeletal metastases treated by surgery. Am J Clin Oncol, 20:424-8.

Coleman RE. 2006. Clinical features of metastatic bone disease and risk of skeletal morbidity. Clin Cancer Res, 12:6243s-9s.

Collette L, van Andel G, Bottomley A, et al. 2004. Is baseline quality of life useful for predicting survival with hormone-refractory prostate cancer? A pooled analysis of three studies of the European Organisation for Research and Treatment of Cancer Genitourinary Group. J Clin Oncol, 22:3877-85.

Cresswell SM, English PJ, Hall RR, et al. 1995. Pain relief and quality-oflife assessment following intravenous and oral clodronate in hormoneescaped metastatic prostate cancer. Brit J Urol, 76:360-5. 
Davis AM, Wright JG, Williams JI, et al. 1996. Development of a measure of physical function for patients with bone and soft tissue sarcoma. Qual Life Res, 5:508-16.

de Haes JCJM, van Knippenberg FCE, Neijt JP. 1990. Measuring psychological and physical distress in cancer patients: structure and application of the Rotterdam Symptom Checklist. Br J Cancer, 62:1034-8.

Di Lorenzo G, Autorino R, Ciardiello F, et al. 2003. External beam radiotherapy in bone metastatic prostate cancer: impact on patients' pain relief and quality of life. Oncol Rep, 10:399-404.

Diel IJ, Body JJ, Lichinitser MR, et al. 2004. Improved quality of life after long-term treatment with the bisphosphonate ibandronate in patients with metastatic bone disease due to breast cancer. Eur J Cancer, 40:1704-12.

Enneking WF. 1987. Modification of the system for functional evaluation in the surgical management of musculoskeletal tumors. In: Enneking WF (ed). Limb Salvage in Musculoskeletal Oncology. New York: Churchill-Livingston, pp. 626-39.

Enneking WF, Dunham W, Gebhardt MC, et al. 1993. A system for the functional evaluation of reconstructive procedures after surgical treatment of tumors of the musculoskeletal system. Clin Orthop Relat R, 286:241-6.

Ernst DS, Tannock IF, Winquist EW, et al. 2003. Randomized, double blind, controlled trial of mitoxantrone/prednisone and clodronate versus mitoxantrone/prednisone and placebo in patients with hormone-refractory prostate cancer and pain. J Clin Oncol, 21:3335-42.

Fernandez-Conde M, Alcover J, Aaron JE, et al. 1997. Skeletal response to clodronate in prostate cancer with bone metastases. Am J Clin Oncol, 20:471-6.

Frankel HL. 1969. Ascending cord lesion in the early stages following spinal injury. Palaplegia, 7:111-8.

Galasko C. 1981. The anatomy and pathway of bone metastases. In: Weiss L, Gilbert A (eds). Bone Metastases. Boston: GK Hall, pp. 49-63.

Gaze MN, Kelly CG, Kerr GR, et al. 1997. Pain relief and quality of life following radiotherapy for bone metastases: a randomized trial of two fractionation schedules. Radiother Oncol, 45:109-16.

Hayes DF, Van Zyl JA, Hacking A, et al. 1995. Randomized comparison of tamoxifen and two separate doses of toremifene in postmenopausal patients with metastatic breast cancer. J Clin Oncol, 13:2556-66.

Heidemann E, Stoeger H, Souchon R, et al. 2002. Is first-line single-agent mitoxantrone in the treatment of high-risk metastatic breast cancer patients as effective as combination chemotherapy? No difference in survival but higher quality of life was found in a multicenter randomized trial. Ann Oncol, 13:1717-29.

Helwig U. 1997. Multiple operations in patients with bone metastases and a prolonged course of disease. Eur J Surg Oncol, 23:59-63.

Hirabayashi H, Ebara S, Kinoshita T, et al. 2003. Clinical outcome and survival after palliative surgery for spinal metastases. Cancer, 97:476-84.

Hultborn R, Gundersen S, Ryden S, et al. 1999. Efficacy of pamidronate in breast cancer with bone metastases: a randomized, double blind placebocontrolled multicenter study. Anticancer Res, 19:3383-92.

Jonler M, Nielsen OS, Groenvold M, et al. 2005. Quality of life in patients with skeletal metastases of prostate cancer and status prior to start of endocrine therapy: results from the Scandinavian Prostate Cancer Group Study 5. Scand J Urol Nephrol, 39:42-8.

Kaasa S, Brenne E, Lund J, Fayers et al. 2006. Prospective randomized multicenter trial on single fraction radiotherapy (8Gyx1) versus multiple fractions $(3 \mathrm{~Gy} \times 10)$ in the treatment of painful bone metastases. Radiother Oncol, 79:278-84.

Kraeber-Bodere F, Campion L, Rousseau C, et al. 2000. Treatment of bone metastases of prostate cancer with strontium- 89 chloride: efficacy in relation to the degree of bone involvement. Eur J Nucl Med, 27:1487-93.

Kristensen B, Ejlertsen B, Groenvold M, et al. 1999. Oral clodronate in breast cancer patients with bone metastases: a randomized study. J Intern Med, 246:67-74.

Lee SH, Kim HS, Kim SR, et al. 2000. Functional outcome following surgical treatment of metastatic tumors involving the femur. Orthopedics, 23:1075-9.
Lipton A, Theriault RL, Hortobagyi GN, et al. 2000. Pamidronate prevents skeletal complications and is effective palliative treatment in women with breast carcinoma and osteolytic bone metastases. Cancer, $88: 1082-90$

Mancini I, Dumon JC, Body JJ. 2004. Efficacy and safety of ibandronate in the treatment of opioid-resistant bone pain associated with metastatic bone disease: a pilot study. J Clin Oncol, 22:3587-92.

Melzack R. 1975. The McGill Pain Questionnaire: Major properties and scoring methods. Pain, 1:277-99.

Manoso MW, Healey JH. 2005. Section 4: Metastatic Cancer to The Bone: Chapter 51: Treatment of Metastatic Cancer. In: DeVita VT, Hellman S, Rosenberg SA (eds). Principles and Practice of Oncology, 7th Edition. Philadelphia, PA: Lippincott, Williams and Wilkins.

Nair N. 1999. Relative efficacy of 32P and 89Sr in palliation in skeletal metastases. J Nulc Med, 40:256-61.

Okuyama T, Korenaga D, Tamura S, et al. 1999. Quality of life following surgery for vertebral metastases from breast cancer. J Surg Oncol, 70:60-3.

Osoba D, Tannock IF, Ernst DS, et al. 1999. Health-related quality of life in men with metastatic prostate cancer treated with prednisone alone or mitoxantrone and prednisone. J Clin Oncol, 17:1654-63.

Perez CA, Brady LW, Halperin EC, et al. 2004. Chapter 87: Palliative of Bone Metastases- Biology and Physiology. In: Principles and Practices of Radiation Oncology, 4th Edition. Philadelphia. PA. Lippincott, Williams and Wilkins.

Pistevou-Gompaki K, Kouloulias VE, Varveris C, et al. 2004. Radiotherapy plus either transdermal fentanyl or paracetamol and codeine for painful bone metastases: a randomized study of pain relief and quality of life. Curr Med Res Opin, 20:159-63.

Plunkett T, Rubens R. 1999. The Biology and Management of Bone Metastases. Crit Rev Oncol Hematol, 31:89-96.

Popov I, Jelic S, Radosavljevic D, et al. 1997. Androgen level variations, clinical response to LHRH agonists and changes in the quality of life subscales in metastatic prostate cancer - speculations about possible role of the monoamine system. Neoplasma, 44:308-13.

Purohit OP, Anthony C, Radstone CR, et al. 1994. High-dose intravenous pamidronate for metastatic bone pain. Brit J Cancer, 70:554-8.

Saad F, Gleason DM, Murray R, et al. Zoledronic Acid Prostate Cancer Study Group. 2002. A randomized, placebo-controlled trial of zoledronic acid in patients with hormone-refractory metastatic prostate carcinoma. J Natl Cancer Inst, 94:1458-68.

Salazar OM, Sandhu T, da Motta NW, et al. 2001. Fractionated half-body irradiation (HBI) for the rapid palliation of widespread, symptomatic, metastatic bone disease: a randomized Phase III trial of the International Atomic Energy Agency (IAEA). Int J Rad Oncol, 50:765-75.

Schipper H, Clinch J, McMurray A, et al. 1984. Measuring the quality of life of cancer patients: the Functional Living Index-Cancer: Development and Validation. J Clin Oncol, 2:472-83.

Schoeggl A, Reddy M, Matula C. 2002. Neurological outcome following laminectomy in spinal metastases. Spinal Cord, 40:363-6.

Siddiqui F, Kachnic LA, Movsas B. 2006. Quality-of-life outcomes in oncology. Hematol Oncol Clin N Am, 30:165-85.

Smeland S, Erikstein B, Aas M, et al. 2003. Role of strontium-89 as adjuvant to palliative external beam radiotherapy is questionable: results of a double blind randomized study. Int J Rad Oncol, 56:1397-404.

Spitzer WO, Dobson AJ, Hall J, et al. 1981. Measuring the quality of life of cancer patients: a concise QL-index for use by physicians. J Chron Dis, 34:585-97.

Steenland E, Leer JW, van Houwelingen H, et al. 1999. The effect of a single fraction compared to multiple fractions on painful bone metastases: a global analysis of the Dutch Bone Metastasis Study. Radiother Oncol, 52:101-9.

Talbot M, Turcotte RE, Isler M, et al. 2005. Function and health status in surgically treated bone metastases. Clin Orthop Relat $R$, 438:215-20.

Townsend PW, Rosenthal HG, Smalley SR, et al. 1994. Impact of postoperative radiation therapy and other perioperative factors on outcome after orthopedic stabilization of impending or pathologic fractures due to metastatic disease. J Clin Oncol, 12:2345-50. 
Turner SL, Gruenewald S, Spry N, Gebski V. 2001. Less pain does equal better quality of life following strontium- 89 therapy for metastatic prostate cancer. Brit J Cancer, 84:297-302.

Van den Hout WB, Van der Linden YM, Steenland E, et al. 2003. Single-versus multiple-fraction radiotherapy in patients with painful metastases: cost-utility analysis based on a randomized trial. $J$ Natl Cancer I, 95:222-9.

Van Holten-Verzantvoort AT, Hermans J, Beex LV, et al. 1996. Does supportive pamidronate treatment prevent or delay the first manifestation of bone metastases in breast cancer patients? Eur J Cancer, 32A:450-4.

Van Holten-Verzantvoort AT, Zwinderman AH, Aaronson NK, et al. 1991. The effect of supportive pamidronate treatment on aspects of quality of life of patients with advanced breast cancer. Eur J Cancer, 27:544-9.

Van Holten-Verzantvoort AT, Kroon HM, Bijvoet OLM, et al. 1993. Palliative pamidronate treatment in patients with bone metastases from breast cancer. J Clin Oncol, 11:491-8.

Vinholes JJ, Purohit OP, Abbey ME, et al. 1997. Relationships between biochemical and symptomatic response in a double blind randomized trial of pamidronate for metastatic bone disease. Ann Oncol, 8:1243-50.

Vitale G, Fonderico F, Martignetti A, et al. 2001. Pamidronate improves the quality of life and induces clinical remission of bone metastases in patients with thyroid cancer. Brit J Cancer, 84:1586-90.

Vogel CL, Yanagihara RH, Wood AJ, et al. 2004. Safety and pain palliation of zoledronic acid in patients with breast cancer, prostate cancer, or multiple myeloma who previously received bisphosphonate therapy. Oncologist, 9:687-95.
Wai EK, Finkelstein JA, Tangente RP, et al. 2003. Quality of life in surgical treatment of metastatic spine disease. Spine, 28:508-12.

Walsh GL, Gokaslan ZL, McCutcheon IE, et al. 1997. Anterior approaches to the thoracic spine in patients with cancer: indications and results. Ann Thorac Surg, 64:1611-8.

Wardley A, Davidson N, Barrett-Lee P, et al. 2005. Zoledronic acid significantly improves pain scores and quality of life in breast cancer patients with bone metastases: a randomized, crossover study of community vs hospital bisphosphonate administration. Brit J Cancer, 92:1869-76.

Ware JE. 1993. SF-36 Health Survey: manual and interpretation guide. Boston, MA: Nimrod Press.

Weigel B, Maghsudi M, Neumann C, et al. 1999. Surgical management of symptomatic spinal metastases. Postoperative outcomes and quality of life. Spine, 24:2240-6.

Weinfurt KP, Castel LD, Li Y, et al. 2004. Health-related quality of life among patients with breast cancer receiving zoledronic acid or pamidronate disodium for metastatic bone lesions. Med Care, 42:164-75.

Weinfurt KP, Li Y, Castel LD, et al. 2005. The significance of skeletalrelated events for the health-related quality of life of patients with metastatic prostate cancer. Ann Oncol, 16:579-84.

World Health Organization. 1948. Constitution of the World Health Organization. Geneva, Switzerland: WHO Basic Documents.

Zigmond AS, Snaith RP. 1983. The Hospital Anxiety And Depression Scale. Acta Psychiatr Scand, 67:361-70. 